I venture to say that an equally favourable opportunity for initiating the reform will not occur until the same almanac is repeated in 1936 , when, however, it is complicated by a leap-day.

The Mary Acre, Brechin, N.B., May 8.

\section{Glossina and the Extinction of Tertiary Mammals.}

Dr. G. D. H. Carpenter (Nature, March 20, p. 46) asks why we should suppose that the occurrence of tsetse-flies (Glossina) in the Miocene of Colorado might have had anything to do with the extinction of some of the large Mammalia. He points out that such flies exist in Africa to-day, carrying trypanosomes, and the native Mammalia nevertheless survive and flourish. It is known, however, that in Miocene times there were extensive migrations of animals, from mammals to insects, and the New and Old Worlds each received important contributions from the other. In such periods of migration it is perfectly conceivable that Glossina might appear in a new region, carrying a trypanosome which would be highly pathogenic for certain elements of the resident fauna. Even in Africa we do not know what animals may be absent to-day owing to the former prevalence of disease-producing organisms.

T. D. A. Cockereil.

University of Colorado, Boulder, Colorado, April 24.

\section{INDICATIONS OF OIL IN DERBYSHIRE.}

A FTER a somewhat lengthy interval, the attenA tion of the public has again been directed to the Government drilling operations for oil in this country. On May 26 the Times described the progress which had been made in the work, and stated that several of the bores had now reached a critical depth. At any moment oil might be discovered. This was followed three days later by the announcement that oil had been found in the Hardstoft No. I boring near Chesterfield. Further details added that the oil had risen Iooo $\mathrm{ft}$. in the well. The form of the announcements was somewhat misleading, and they need to be stripped of their trappings to arrive at a true perspective. A show of oil has been found at Hardstoft-nothing more. Such shows of oil have been found before in the British strata, and have invariably proved to be of little or no value. It remains to be proved that the present indications at Hardstoft are of a different calibre, and it would have been well to postpone, or at least moderate, the announcement of the discovery until the resumed drilling operations had indicated the quantity of oil which was forthcoming.

The position of the general drilling operations in Britain may be summarised as follows. Wells are being drilled in three areas, Chesterfield, North Staffordshire, and Midlothian. The operations in the last two areas are merely in their preliminary stages, but in the Chesterfield region the work is further advanced, and two of the seven wells-namely, Brimington and Hardstoft No. I -have almost attained their proposed depths. Shows of gas have been encountered in several of the bores, but the porous horizons of the Millstone Grits, where pierced, have in all cases failed to produce the oil which was anticipated. To this extent, then, the results have been disappointing. However, it has never been intended to limit exploitation to the Millstone Grits. The underlying Carboniferous Limestone has been considered by some to be a better horizon for testing, and the wells are being continued through the Yoredale Shales in order to pierce this formation. Both the Hardstoft No. I and Brimington bores have almost reached the Carboniferous Limestone, and the oil which is announced in the former probably comes from the beds near the junction.

It must be emphasised that there is nothing in the present situation to warrant the unduly optimistic attitude of a section of the Press. The statement that this is the first discovery of oil in substantial quantity in England is incorrect, and greatly exaggerates the present indications. The announcement that the oil has risen $1000 \mathrm{ft}$. in the well may bear two interpretations. It may be that the whole liquid column is composed of oil, or it may be merely an upper layer of oil floating on a column of water, as in the case of the Kelham bore. The shales and banded limestones immediately above the main limestone in Derbyshire often contain small quantities of petroleum, though the porosity of these strata is too small to yield large quantities of the material. It is possible that every well which is sunk into these beds will yield some indications of petroleum, but the small porosity and other factors of preservation limit the hope of a commercial production of petroleum.

Judgment must be suspended until the results of the resumed drilling operations are known. In the meantime it is fortunate that the Government has prevented promiscuous drilling, and thus minimised the evils of fevered financial speculation. The Canadian oil boom of Igi4, based on an oil show similar in type to the present indications at Hardstoft, and which ended in nothing, is a typical example of these deplorable scrambles.

$$
\text { V. C. Illing. }
$$

\section{THE SOLAR ECLIPSE.}

TELEGRAMS received by the Astronomer Royal report that at the station at Sobral, in Brazil, occupied by Dr. Crommelin and $\mathrm{Mr}$. Davidson for photographing the field of stars round the sun on the occasion of the total eclipse of the sun last week (May 29), the sky was clear for at least part of totality, and that the programme was satisfactorily carried out. The photographs have been developed, and all the stars expected are shown on the plates taken with the astrographic lens, as well as on those taken with a second telescope lent by Father Cortie. The expedition will remain at Sobral until the necessary comparison photographs are taken in situ. The message from Prof. Eddington at Prince's Island, off the coast of West Africa, which reads "Through cloud, hopeful," may be taken to imply that some success will also be derived from the work of this expedition. 